\title{
A new lizard (Reptilia: Squamata) from the Lower Cretaceous Yixian Formation of China, with a taxonomic revision of Yabeinosaurus
}

Liping DONG ${ }^{1}$, Yuan WANG ${ }^{1}$ and Susan E. EVANS ${ }^{2^{*}}$

${ }^{1}$ Key Laboratory of Vertebrate Evolution and Human Origins of Chinese Academy of Sciences, Institute of Vertebrate Paleontology and Paleoanthropology, Chinese Academy of Sciences, 142 Xi-Zhi-Men-Wai St, P.O. Box 643, Beijing, 100044, China. dongliping@ivpp.ac.cn; wangyuan@ivpp.ac.cn

${ }^{2}$ Department of Cell and Developmental Biology, University College London, Gower Street, London, WC1E 6BT, UK. s.e.evans@ucl.ac.uk

\begin{abstract}
Yabeinosaurus was the first lizard genus described from the Early Cretaceous Jehol Biota of China. The holotype of the type species, $Y$. tenuis, is an immature skeleton but it has been lost for decades. A second species, Y. youngi, was erected based on another immature skeleton and is distinguished by its longer, more gracile limbs. In 2001, a juvenile skeleton from the Jingangshan locality of Liaoning was designated as the neotype for $Y$. tenuis. Subsequently, several further specimens from other localities, juvenile and adult, have been attributed to this species. Here we describe a second lizard specimen from the neotype locality. In anterior tooth shape, finger-like mandibular angular process, cranial sculpture, maxilla shape, and short, robust humerus, the new specimen resembles adult and subadult material currently attributed to $Y$. tenuis, but it differs in having bicuspid posterior teeth and a straight rather than a hooked angular process of the mandible. We propose a new species (Y. bicuspidens sp. nov.) for this specimen which represents the first occurrence of bicuspid teeth in an Early Cretaceous lizard from China. However, the recognition of a second species at the neotype locality raises a taxonomic problem. Due to the immaturity of the designated holotype and neotype of $Y$. tenuis, they cannot be coded for the jaw and dental characters that distinguish the two robust-limbed species. This renders Yabeinosaurus tenuis a nomen dubium. Here we propose that Yabeinosaurus tenuis should be treated as a historic taxon, permitting retention of the generic name under ICZN rules, and erect a second new species (Y. robustus sp. nov.) for the principal robust-limbed
\end{abstract}


morphotype in the Jehol Biota with monocuspid posterior teeth and a hooked angular process.

Keywords: China, lizard, Yabeinosaurus, Cretaceous Jehol Biota, taxonomy

* Corresponding author

\section{Introduction}

The Yixian and Jiufotang formations of northeastern China have yielded an exceptional and diverse Early Cretaceous faunal and floral assemblage, including some of the most complete lizard specimens of this age anywhere in the world (Chang et al., 2008; Evans and Wang, 2012; Sweetman, 2016; Zhou, 2014). The first lizard to be described, Yabeinosaurus tenuis (Endo and Shikama, 1942), was based on a single immature specimen (Central National Museum of Manchoukuo [CNMM] 3735) from the Yixian Formation at Tsaotzushan (alternative transliteration Zaocishan), in what is now Liaoning Province. Endo and Shikama suggested the new taxon might be related to gekkotans, a position accepted by subsequent reviewers (e.g. Estes, 1983; Hoffstetter, 1967). The holotype was lost or destroyed during the Second World War, leaving a description, photographs, and some figures for comparison. Some years later, C. C. Young [Yang, Z.-j.] (1958) described a second Yixian lizard specimen (Institute of Vertebrate Paleontology and Paleoanthropology [IVPP] V 961) from the locality of Ketzutung (Gezidong), also in Liaoning. He referred it to Yabeinosaurus tenuis, saying that it was so like the original type specimen in size and morphology as to make a description 'superfluous'. However Hoffstetter (1964) made IVPP V 961 the type of a new species, Yabeinosaurus youngi, based on putative differences between this specimen and the original. A third, small, lizard specimen (Liaoning, Beipiao, Vertebrate [LBV] 92009 housed in the Geological Museum of China) from Shangyuan, Beipiao, western Liaoning, was referred to Y. tenuis in 1995 (Ji, 1995), and in 2001, Ji et al. proposed a neotype (Yizhou Fossil Museum [YFM] R002) for the species. The neotype specimen was from Jingangshan, two and a half kilometres southwest of the type locality and, again, represented an immature animal.

Over the last decade, with an intensification of collecting activity in the Yixian and Jiufotang formations, many other Yabeinosaurus-like lizard specimens have been recovered (Fig. 1). These allowed the 
recognition of a growth sequence (Evans et al., 2005), from small specimens (e.g. IVPP $\vee$ 12641), through subadults (e.g. IVPP $\vee 13284$ ), to large robust adults (e.g. IVPP $\vee 13285$ ) up to $300-350 \mathrm{~mm}$ in snout-pelvis length (SPL, premaxilla to the posterior edge of the second sacral vertebra). It is the smallest specimens that match the original Tsaotzushan holotype (as illustrated in Endo and Shikama, 1942) in terms of size, proportions (e.g. relatively short robust limb elements), and general morphology (e.g. paired frontals, short maxilla, small rectangular nasals). Yabeinosaurus tenuis was thus misinterpreted as a gekkotan for more than sixty years before the work by Evans et al. (2005), because all previously described specimens were weakly ossified juveniles.

The holotype of $Y$. youngi (IVPP $\vee 961$ ) is little more than a shallow impression containing a few bone fragments. Re-examination (Evans and Wang, 2012) failed to confirm the cranial differences described by Hoffstetter (1964), but the limb elements are certainly proportionally longer and more gracile than those of specimens referred to $Y$. tenuis, supporting at least specific distinction (Table 1). The generic status of $Y$. youngi remains uncertain. Nonetheless, its recognition seemed to confirm the presence of two distinct Yabeinosaurus-like species, one (Y. youngi) with long gracile limbs and one (Y. tenuis) with shorter, more robust limbs. The majority of existing specimens could be attributed to the robust-limbed morphotype, even as juveniles. The juveniles appeared to provide a morphological bridge between the robust adults and the original Tsaotzushan type, allowing referral of the new specimens to Yabeinosaurus (Evans et al., 2005; Evans and Wang, 2012; Wang and Evans, 2011).

Here we describe a new lizard specimen, IVPP V 15840, from the Jingangshan locality that yielded Ji et al.'s (2001) proposed neotype. The new specimen generally resembles adults and subadults referred to Yabeinosaurus tenuis (Evans et al., 2005; Evans and Wang, 2012), and is similar in size to adult specimens previously referred to that species. However, it differs in having bicuspid posterior teeth on the maxilla, and a straight rather than hooked angular process on the mandible. These differences are suggestive of specific distinction and this discovery documents the first record of bicuspid teeth in an Early Cretaceous lizard from China, providing a new dental morphotype that can be compared to neighbouring areas in East Asia. However, this new specimen raises taxonomic problems with respect to the status of $Y$. tenuis.

\section{Geology and materials}

The continental deposits of the Jehol Group outcrop across northeastern China (northern Hebei, western 
Liaoning, and southeastern Inner Mongolia) and include an outstanding series of highly fossiliferous horizons that have revolutionized our understanding of the evolution of many vertebrate groups. The age and geology of these deposits have been described in detail by numerous authors (e.g., Chang et al., 2009; Chen et al., 2015; He et al., 2004, 2006; Pan et al., 2013; Wang and Zhou, 2003; Zhou et al. 2003; Zhu et al., 2007) and these works should be consulted for a comprehensive discussion of age and lithology.

Current consensus (e.g. Chang et al., 2009) generally limits the Jehol Group to the Yixian Formation and the overlying Jiufotang Formation, although some researchers (e.g. Pan et al., 2013) also include the younger (Albian) Fuxin Coals. The Yixian Formation varies in thickness from 225-4000 metres across its geographical range (Chang et al., 2009) and is composed of rocks deposited in a primarily lacustrine environment, with some terrestrial and fluvial horizons. Until recently, Chinese researchers recognised four major divisions of the Yixian Formation: Lujiatun, Jianshangou, Dawangzhangzi and Jingangshan from below upward (e.g. Wang and Zhou, 2003). However, although the Lujiatun and Jianshangou beds represent different facies, they are now thought to be of similar age (e.g. He et al., 2006). Multiple tuff horizons through the Jehol Group have yielded 40Ar/39Ar age estimates, but it is important to note that deposition may not have been synchronous across all localities (Chen et al., 2015). Recent work in western Liaoning (Chang et al., 2009), from which all currently known Yabeinosaurus specimens are derived, has yielded a date of $129.7 \pm 0.5 \mathrm{Ma}$ for basalts at the base of the Lujiatun Bed, and a date of $122.1 \pm 0.3 \mathrm{Ma}$ for a tuff at the base of the Jiufotang Formation, giving a span of roughly seven million years for the Yixian Formation as a whole. The Jiufotang Formation itself ranges in thickness from 206-2685 metres (Chang et al., 2009). A 40Ar/39Ar date of $110.59 \pm 0.52 \mathrm{Ma}$ is recorded for an intrusive basalt within the formation (Eberth et al., 1993) and an age of $120.3 \pm 0.7 \mathrm{Ma}$ based on $40 \mathrm{Ar} / 39 \mathrm{Ar}$ dating on sanidine crystals from tuffs found interbedded within the fossil-bearing deposits is obtained later (He et al., 2004). However, Chang et al. (2009) were more circumspect about the upper age limit. Underlying the Yixian Formation (unconformably) are the Tuchengzi Formation, the Tiaojishan Formation (=Lanqi Formation), and the Jiulongshan Formation (=Haifanggou Formation). A 40Ar/39Ar date of $139.4 \pm 0.19$ Ma has been recorded from the upper part of the Tuchengzi Formation (Chang et al., 2009; Swisher et al., 2002), and dates of 160.7 $\pm 0.4 \mathrm{Ma}$ and $158.7 \pm 0.6$ Ma were reported for tuffs from the lower part of the Tiaojishan (=Lanqi) Formation (Chang et al., 2014), indicating that the underlying Jiulongshan Formation is of Middle Jurassic age.

Specimens of the lizard genus Yabeinosaurus have been recovered from several horizons and 
localities within the Yixian and Jiufotang formations of western Liaoning, in addition to referred material ('Yabeinosaurus' youngi) from the Middle Jurassic Jiulongshan Formation (Fig. 1) (Evans et al., 2005; Evans and Wang, 2012; Wang and Evans, 2011).

The new lizard specimen, IVPP $\underline{\mathrm{V} 15840 \text {, housed in the collections of the Institute of Vertebrate }}$ Paleontology and Paleoanthropology, Chinese Academy of Sciences, Beijing, came from a horizon within the Jingangshan Bed at the top of the Yixian Formation at the Jingangshan locality, Yixian County, Liaoning Province, China (Fig. 1). This locality has previously yielded juvenile specimens of Yabeinosaurus (Evans et al. 2005, Evans and Wang, 2012), as well as fish (Lycoptera), turtles (Manchurochelys), choristoderes (Monjurosuchus) (Wang et al., 2005), pterosaurs (Lü et al., 2012; Wang and Zhou, 2004), birds (Zhang and Zhou, 2004), and many invertebrates and plants (Wang et al., 2014; Wang et al., 2015).

The new species names proposed in this manuscript have been registered with Zoobank (http://zoobank.org/), the official register of Zoological Nomenclature, under the unique digital Zoobank register identifiers: Yabeinosaurus bicuspidens sp. nov (Isid:zoobank.org:act:B3B538F3-5F81-4F4C-ADE53A4C52C33839) and Y. robustus sp. nov. (Isid:zoobank.org:act:FC4B27C0-E0F6-49D8-A3EB0E7C8652A108).

Institutional Abbreviations: CNMM, Central National Museum, Manchuria; IVPP V, Institute of Vertebrate Paleontology and Paleoanthropology, Vertebrate collections, Chinese Academy of Sciences, Beijing; LBV Liaoning Beipiao Vertebrate, Geological Museum of China; YFM, Yizhou Fossil Museum, Yixian County, Liaoning.

\section{Systematic Palaeontology}

3.1 The genus Yabeinosaurus

Lepidosauria Haeckel, 1866

Squamata Oppel, 1811

\section{Yabeinosaurus Endo and Shikama 1942}

Type species. Yabeinosaurus tenuis Endo and Shikama 1942 (nomen dubium)

Range. Lower Cretaceous of China, Jianshangou Bed, Yixian Formation (ca.124. Ma) to Jiufotang Formation (ca.120 Ma, Chang et al., 2009; He et al., 2004) of Liaoning. 
Diagnosis. (Revised from the diagnosis in Evans and Wang, 2012): A genus of lizard with large adult size; vermiculate cranial sculpture; a single median premaxilla with nine tooth positions; maxilla with deep facial process and short orbital process; marginal dentition pleurodont; anterior maxillary and dentary teeth conical, unicuspid, and slightly recurved; a biradiate jugal; jugal arch (=postorbital bar) complete (contra Endo and Shikama, 1942; Estes, 1983); enlarged postfrontal that almost fills the upper temporal fenestra; elongate postorbital with reduced orbital component; postfrontal and postorbital separate but closely integrated; interdigitated frontoparietal suture; parietal longer than wide, fully enclosing large parietal foramen; supratemporal processes with wide bases that lie in the same plane as the parietal body; dentary with long narrow angular process.

Remarks. The status of Y. youngi remains problematic (Evans and Wang, 2012), but we retain it as a valid historic species given that the type specimen is preserved in the IVPP collection (IVPP V 961), and it remains possible that new material will be recovered showing a combination of cranial and postcranial features consistent with the original specimen. The specimen was recovered from the Jiulongshan Formation (=Haifanggou Fm) at Gezidong (Ketzutung) Locaility, Lingyuan City, Liaoning Province, a horizon now generally considered to be of Middle Jurassic age (Chang et al., 2009). A juvenile lizard from the Middle/Late Jurassic Daohugou locality of Inner Mongolia (Evans and Wang, 2007) shows proportional similarities to juvenile specimens attributed to Yabeinosaurus. These two specimens may extend the range of Yabeinosaurus into the Jurassic, but more diagnostic material is needed of each.

\subsection{Yabeinosaurus bicuspidens sp. nov.}

Etymology. Species name reflects the bicuspid posterior dentition in the maxilla.

Isid:zoobank.org:act:B3B538F3-5F81-4F4C-ADE5-3A4C52C33839

Holotype. IVPP V 15840, housed at the Institute of Vertebrate Paleontology and Paleoanthropology, Chinese Academy of Sciences, Beijing, associated but disarticulated bones on a slab of shale, preserving a right maxilla, a right jugal and ectopterygoid, a right pterygoid, a median premaxilla, both mandibles, and postcranial bones including a humerus.

Range. Jingangshan Bed, Yixian Formation, Lower Cretaceous (ca. 121.6 Ma, Aptian: Liang et al., 2012). Locality and horizon. Jingangshan Locality, Jinzhou City, Yixian County, Liaoning Province, China (E120.88, 
N41.53); Jingangshan Bed, at the top of the Yixian Formation, Jehol Group, Lower Cretaceous

Diagnosis. Species of Yabeinosaurus resembling Y. robustus sp. nov. in reaching large adult size (at least $350 \mathrm{~mm}$ total length by comparison with complete specimens of $Y$. robustus) and in having a relatively short robust humerus (contra Y. youngi), but differing in the possession of bicuspid teeth in the posterior part of the maxillary tooth row, and in having a straight rather than hooked angular process on the mandible.

\section{Description.}

IVPP V 15840 (Fig. 2A,B) is preserved on a small slab of grey, silicious silty shale, bearing a right maxilla, a median premaxilla (Fig. 3A), a right jugal and ectopterygoid, a possible squamosal or supratemporal (Fig. 3B), a right pterygoid (Fig. 3C), both mandibles, a small cluster of broken ribs, a humerus and a biradiate bone that might be a partial interclavicle (Fig. 2). As the bones are close together and no repetition is observed, we infer that they belonged to one individual. The right mandible is $33.8 \mathrm{~mm}$ in length, the left is $33.9 \mathrm{~mm}$. The humerus is $13.3 \mathrm{~mm}$ long. Compared to similar lizards from the Jehol Biota, this corresponds to an SPL of $130-140 \mathrm{~mm}$.

Skull and lower jaws. The right maxilla preserves most of the alveolar margin and part of the posterior orbital process. The external surface bears rough linear sculpture like that of Yabeinosaurus tenuis and the suborbital process is short. There are $\sim 21$ tooth positions in all (possibly with one or two missing anteriorly), and there are gaps in the dentition that suggest replacement was active. This compares with $\sim 25$ maxillary teeth recorded for adults attributed to $Y$. tenuis. The premaxilla is disarticulated and lies to the right of the left lower jaw. It is preserved in lingual view (Fig. 3A), with the right side almost complete but the left damaged laterally. The median tooth appears to be flanked on the right by four tooth positions, suggesting a total count of nine premaxillary teeth. The teeth resemble those of the anterior maxilla but are slightly smaller. The nasal process is long and triangular in cross-section (apex posterior due to a posterior median ridge) (Fig. 3A), but the tip flattens out where it met the nasals.

The right jugal is preserved posterior to the maxilla (Fig. 2), although it has lost much of the bone surface along its ventral part. The bone is sickle-shaped, with a roughly parallel-sided maxillary process and a slightly shorter postorbital process that has a tapering tip. From its angle, this may not have reached the squamosal. Three scleral ossicles are preserved in the orbit, above the curve of the jugal.

To the right of the left mandible, anterior to the premaxilla, there is a very slender rod-like element with a 
slight angulation. This is not an epipterygoid as the bone is compressed rather than rounded in crosssection, and seems to have a facet on the surface of its wider exposed surface (tip closer to the jaw) (Fig. $3 C$ ). The most likely candidates would be squamosal or supratemporal, although it seems rather small for the former.

The only other potential component of the skull roof is a large element overlying the anterior tips of the lower jaws posteriorly and the right maxilla anteriorly. The surface appears to bear sculpture but it is otherwise uninformative and crushed.

The palate is represented by an ectopterygoid and a right pterygoid. The ectopterygoid overlaps the right jugal, and presumably belongs to that side, but the pterygoid is displaced anteriorly and to the right. The ectopterygoid (Fig. 2) has a narrow lateral head which was probably originally horizontal in orientation and a bifurcate medial head that clasped the lateral margin of the pterygoid. The pterygoid (Fig. 2, Fig. 3B) is preserved in dorsal view. It is complete and preserves a tapering palatal plate, with facets for the palatine medially and ectopterygoid laterally, separated by an embayment leading into a groove corresponding to the edge of the suborbital fenestra. The most striking feature is a long slender anteromedial extension that probably met the vomer. The lateral process is facetted for the ectopterygoid but it is small and, taken together with the ectopterygoid morphology, the pterygoid flange seems to have been shallow and rather weak. Posteriorly, the pterygoid angles and narrows into a slender quadrate process that ends in a pointed tip bearing a longitudinal dorsomedial fossa for the origin of the pterygoideus muscle. At the junction of the palatal plate and quadrate process is a pit (fossa columellae) for the base of the epipterygoid and a recess for the basipterygoid process.

Both mandibles are preserved but the bone surfaces are damaged and little detail is visible. The dentaries are long and rather shallow. The left bone has $\sim 18$ visible tooth positions. The right dentary is broken ventrally providing a view into the tooth bases. This demonstrates that the tooth row extended further posteriorly than is obvious on the left side, so there were probably at least 23 positions, which would be consistent with the maxillary + premaxillary tooth numbers. The right mandible is somewhat better preserved than the left. It bears a large coronoid with a strong dorsal process, the tip of which is angulated posteriorly. The surangular dorsally and prearticular ventromedially provide clear outlines. Above and anterior to the prearticular is a relatively deep angular. The articular is strongly built. It is extended into a prominent angular process and a short retroarticular process. The angular process protrudes medially at right angles to the long axis of the jaw. The angular process is not preserved on the left mandible of the new specimen, but the 
retroarticular process is more complete, and is seen to be short and rather square, with a shallow dorsal concavity.

Dentition. The anterior ten maxillary teeth are slender and slightly recurved (Fig. 4A) but the posterior eight teeth of the maxillary row have crowns that are slightly expanded mesiodistally, and are essentially bicuspid (a small anterior cusp and a larger posterior cusp) (Figs. 4B, 4C). An incipient third cusp is visible on some teeth, but not in a symmetrical arrangement with the anterior cuspule (Fig. 4C). In addition, the cusped apical margin appear thinner than the tooth base (Fig. 4C). The posterior cuspid teeth also have a peculiar labial wear pattern with two distinct dorso-ventral facets separated by a narrow unfacetted area (seen most clearly in Fig. 4C). The wear appears too constrained to represent tooth to food wear but the lower dentition should be biting lingual to the maxillary teeth, not labial to them. Whether this is pathological or reflects an unusual jaw action is impossible to determine without further material.

The dentary teeth are slightly smaller than those on the maxilla. Given four premaxillary and an estimated 21 maxillary teeth on each side of the upper dentition, there should be approximately 25 teeth in the dentary. However, allowing for one missing tooth in the symphysial region and one empty tooth position, only the first 18 dentary teeth are preserved. We cannot therefore confirm whether or not the posterior dentary teeth were bicuspid like those of the maxilla.

Postcranial skeleton. Adjacent to the pterygoid is a mass of bone fragments (shown in the digital image but not the drawing in Fig. 2), mostly incomplete ribs. In addition to these, two postcranial bones are preserved on the block (Fig. 2). Between the lower jaws, there is a relatively short robust humerus in which the distal condyles are shown in impression and were presumably not ossified at the time of death, suggesting the animal was not fully mature. Further posteriorly, and at the edge of the block, there is a bifurcate bone that could be a partial interclavicle, with only one of the two lateral arms preserved.

Comparison and interpretation of IVPP V 15840. The specimen is frustratingly incomplete. It shares a number of characters with subadult and adult specimens previously referred to $Y$. tenuis (vermiculate maxillary sculpture; nine premaxillary teeth; acuminate anterior maxillary teeth (Figs. 4D-F); short orbital process of the maxilla; single premaxilla; long slender vomerine ramus of the pterygoid; prominent finger-like angular process; sharp slightly recurved anterior teeth, sickle-shaped jugal, short robust humerus, possibly cruciform interclavicle) but does not preserve the characteristic expanded postfrontal and reduced postorbital, nor the palatal dentition. Moreover, it differs in the shape and orientation of the angular process 
(straight and medially directed rather than hooked) and in the unusual bicuspid posterior maxillary teeth. No sub-adult or adult specimen previously referred to Y. tenuis shows bicuspid posterior maxillary teeth (Figs. 4E, 4G). The preservation of the posterior teeth in the holotype of $Y$. youngi is too poor to determine whether they might have been bicuspid, but $Y$. youngi has relatively longer and more gracile humeri (Evans and Wang, 2012). In IVPP V 15840, the humerus is $39 \%$ of the mandible length, a value that falls within the $99.9 \%$ confidence interval of specimens previously attributed to $Y$. tenuis, unlike $Y$. youngi at $69 \%$ (see Table 1). Thus the new Jingangshan lizard can be differentiated from adult or near-adult specimens previously referred to $Y$. tenuis on a combination of dental and mandibular characters, and from $Y$. youngi on limb proportions, but the similarities suggest it belongs to the same generic or suprageneric grouping. This suprageneric grouping includes the related Japanese Sakurasaurus (Barremian-Aptian, Tetori Group, Evans and Manabe, 1999, 2009) which closely resembles Yabeinosaurus in features of the skull and dentition, and is placed as its sister taxon in phylogenetic analysis (Evans and Manabe, 2009; Evans and Wang, 2012). Like IVPP V 15840, adults of Sakurasaurus are heterodont, combining sharp recurved anterior teeth on both the maxilla and dentary with specialised posterior teeth, although the posterior teeth in Sakurasaurus are blunt and striated rather than bicuspid as in the new Chinese specimen.

Bicuspid teeth are relatively rare in Jurassic-Lower Cretaceous lizards. Amongst European genera, bicuspid teeth have been recorded in Meyasaurus (Lower Cretaceous of Spain, e.g., Evans and Barbadillo, 1997; Richter, 1994; and England, Sweetman, 2009; Sweetman and Evans, 2011), Pedrerasaurus (Lower Cretaceous of Spain, Bolet and Evans, 2010), and Durotrigia (Berriasian, England, Hoffstetter, 1967), although the latter taxon is represented by a single eroded fragment of dentition and is here considered to be a nomen dubium. Jaws with bicuspid teeth are also recorded from the Lower Cretaceous of Japan (Evans and Matsumoto, 2015) but are either too fragmentary to be named (Morphotype A) or bizarre and highly derived (Hakuseps). Bicuspid teeth are suited to piercing and fracturing the chitinous exoskeletons of insects. However, IVPP V 15840 combines conical and slightly recurved anterior teeth, suited for prehension, with bicuspid posterior teeth that are labiolingually compressed and may have had a cutting edge. Those features, and the peculiar labial faceting on the maxillary teeth, suggest that the lizard represented by IVPP V 15840 may have had a more specialised diet than some of the other Jehol lizards.

The angular process of the mandible protrudes medially at right angles to the long axis of the bone, unlike the corresponding process of IVPP V 13285 (Figs. 4H, 4I), a large specimen previously referred to Y. tenuis but now the holotype of $Y$. robustus sp. nov. which is hook-like and angles forward (Evans et al., 
2005).

\subsection{Yabeinosaurus robustus sp. nov.}

Etymology. As in robust, to recognise the large size and robust build of the adult lizard.

Isid:zoobank.org:act:FC4B27C0-E0F6-49D8-A3EB-0E7C8652A108

Holotype. IVPP V 13285, housed at the Institute of Vertebrate Paleontology and Paleoanthropology, Chinese Academy of Sciences, Beijing, a well prepared adult skull and manus, figured in Evans et al., (2005: figs. 1, 2, 4-6, 8-10, 14).

Locality and horizon. Sihetun Locality, Liaoning Province, China (E120.80, N41.59); Jianshangou Bed, Lower Cretaceous (ca. 124.6 Ma, Aptian), of the Yixian Formation.

Referred specimens. IVPP V 13284 from the Dawangzhangzi Bed, Yixian Formation, Liaoning, China (Evans et al., 2005); V 13272, IVPP V 16361, 16362, from the Jiufotang Formation, Liaoning Province, China (Evans and Wang, 2012); IVPP V 18005, from the Jiufotang Formation, Liaoning Province, China (Wang and Evans, 2011) (see Fig.1 for locality data).

Range. Lower Cretaceous, China, Jianshangou Bed, Yixian Formation to Jiufotang Formation, Liaoning Province, China (ca.124.6 Ma-120 Ma [Chang et al., 2009; He et al., 2004, 2006]).

Diagnosis. (Revised from the diagnosis of Y. tenuis in Evans and Wang, 2012): a lizard with adult size in the range 300-350 mm; pit for processus ascendens of supraoccipital deep, and extending vertically into parietal; jugal with short posterior spur in adult; quadrate with distinct pterygoid lappet; palatine and pterygoid toothed; pterygoid with slender quadrate process; lower jaw of mature adult characterized by hook-shaped angular process; vertebrae procoelous with broad, rounded centra and large subcentral foramina; second sacral rib unusually strongly built; clavicle of adult robust, medially expanded and perforate; astragalus and calcaneum co-ossify late in development; small round osteoderms present but do not form a contiguous mass. This species resembles Y. bicuspidens sp. nov. and differs from Y. youngi in the possession of a humerus that is less than $50 \%$ of mandibular length, but differs from Y. bicuspidens sp. nov. in the possession of unicuspid posterior maxillary teeth (Fig. 4E-G) and a hook-shaped rather than straight angular process on the mandible (Fig. 4H, I).

Note that some of the characters listed in the above diagnosis may be found to be more widely distributed 
within the genus if more complete specimens of other species are recovered.

Description See Evans et al., (2005), Evans and Wang (2012), Wang and Evans (2011).

Remarks. The justification for this taxonomic revision of Yabeinosaurus is discussed in detail below (4. Discussion). We have selected IVPP V 13285 (Evans et al., 2005) as the holotype of Y. robustus sp. nov., rather than more complete skeletons from the Jiufotang Formation (Evans and Wang, 2012), because IVPP V 13285 represents a fully mature individual, and preparation has allowed access to both dorsal and palatal surfaces of the skull. Although there is only a partial forelimb, it is clear that this represents a robust rather than gracile limb morphology (Table 1).

IVPP V 12641, a juvenile skeleton, was included in the revised description of Evans et al. (2005). As this specimen is from Jingangshan, the locality that yielded both Ji et al.'s (2001) neotype of Y. tenuis and the holotype of Y. bicuspidens, it is best attributed to Yabeinosaurus sp. as it cannot be coded for either the posterior dentition or the shape of the angular process.

\section{Discussion}

\subsection{The holotype of Yabeinosaurus tenuis}

As explained above (1. Introduction), the Tsaotzushan holotype (CNMM 3735, Endo and Shikama, 1942) has been lost. Whether it was destroyed during the Second World War, moved to a forgotten location, or taken to Japan remains unknown, but it is not in the palaeontological collections of the National Museum in Tokyo (confirmed by SEE). Endo and Shikama (1942) diagnosed Yabeinosaurus tenuis as follows: small aquatic lizard with elongate body and tail; head moderate size, neck short; five cervical and 20 other presacral vertebrae; vertebrae procoelous; dorsal ribs slender, curved; no abdominal ribs; rostrum short, and broad with obtuse tips; narial opening small, orbit large; postorbital not joined to jugal; quadrate movable, joined to squamosal; teeth pleurodont, acutely conical and curved backward; pectoral and pelvic girdle not well developed; limbs short; anterior limb shorter than posterior; phalangeal formula ?3453 (manus) and $2345 ? 4$ (pes); claws present, fourth digit longest; no epidermal scales except the platycaudal uniserial scales.

Endo and Shikama did not explain why they interpreted Yabeinosaurus as aquatic, but it may have been because the same slab contained fish remains (as is common in these deposits). By modern standards, their diagnosis is inadequate. Most of the features they list are generalised reptilian characters 
(elongate body and tail, shorter forelimbs, moderate sized head, narial opening small, claws present, phalangeal formulae) or squamate characters (mobile quadrate, no gastralia), or they reflect immaturity (large orbits, slender ribs, poorly developed girdles, absence of scales [presumably they meant osteoderms]). Procoely is a derived character, but it occurs in a majority of squamates, as does pleurodonty. That leaves sharp recurved teeth, short limbs, 'postorbital not joined to jugal', and 'five cervical and 20 other presacral vertebrae' to diagnose the taxon. The latter two could be diagnostic. However, the apparent failure of the jugal to reach the 'postorbital' is probably a misinterpretation based on a combination of skeletal immaturity and compression (causing the loosely connected bones to separate), and a misunderstanding of the anatomy. No postfrontal was figured or described in the paper and it is more likely that the authors misinterpreted an enlarged postfrontal, as recorded for adult Yabeinosaurus (Evans et al., 2005; Evans and Wang, 2012), for a postorbital, although without the specimen or a high resolution photograph, this cannot be confirmed. Similarly, five cervical vertebrae would be unusual but, from the drawing in their Plate V (Endo and Shikama, 1942), this count clearly did not include the atlas. Moreover, distinguishing the last cervical from the first dorsal is difficult with a detached and disarticulated pectoral girdle. Thus a typical squamate count of seven or eight cervicals and 18-19 dorsals is equally plausible.

Endo and Shikama's description of the specimen again mostly records generalised reptile/lizard characters and proportions, although the figures add a few additional characters notably: paired frontals, relatively small rectangular nasals; a long slender squamosal; a rather small quadrate; a short deep maxilla; and relatively robust, though short, limb elements.

\subsection{The Jingangshan neotype}

The proposed neotype (YFM R002, Ji et al., 2001) does not come from the same locality as the holotype, but from a neighbouring one. Its attribution to $Y$. tenuis is based primarily on size and proportions. The similarity in size simply reflects the fact that both it and the original holotype were juvenile individuals. This is obvious from the images, but Ji et al. (2001) also noted that only one carpal bone is ossified, the scapula and coracoid are not co-ossified, and the only visible pelvic element is an ilium, demonstrating that the pelvic bones were also still separate. These features are all indicative of immaturity. The described lack of a connection between the jugal and skull roof, like that in the holotype description, is therefore likely to result from distortion in a weakly ossified skull. Ji et al. (2001) listed a series of shared 'characters' to support their 
proposal that the morphology of YFM R002 is identical to that of the lost holotype, but the majority are features that would be found in the skeleton of any unspecialised juvenile lizard. The only character listed by $\mathrm{Ji}$ et al. that could be considered derived, if correct, is the count of five cervical vertebrae, instead of the seven or eight found in most lepidosaurs. However, this count is doubtful for similar reasons to those discussed above for the holotype. Firstly, it is clear from their figure of the YPM R002 that the cervical region is incompletely preserved, because the specimen is twisted. Secondly, without a fully articulated pectoral girdle and first thoracic rib, it is difficult to distinguish posterior cervical vertebrae from anterior dorsals.

Referral of YPM R002 to Yabeinosaurus tenuis is thus at best tentative. It is simply a weakly ossified juvenile lizard skeleton of similar size to the original holotype. However, even if YPM R002 is attributable to Y. tenuis, its designation as a neotype serves no useful purpose. According to the ICZN, the loss of a holotype does not necessitate the designation of a neotype if the species can be identified: from the original description, especially if photographs are supplied; by examination of topotypic material (from the type locality); or by generally accepted interpretations that can be followed. Although the original description is inadequate by modern standards, YPM R002 adds nothing to it. It does not therefore stabilise the species or aid future researchers. In this regard, it resembles 'Jeholacerta' (Ji and Ren, 1999), an immature specimen that is mainly a skin impression, and 'Liaoningolacerta' (Ji, 2005), 'diagnosed' almost exclusively on juvenile character traits.

\subsection{Recent material}

Prior to 2001, Yabeinosaurus tenuis was thus based on a limited original description with drawings and two low resolution photographs, a lost holotype, and an uninformative neotype. However, a new and larger collection of Yixian Formation lizard specimens in the IVPP, Beijing, allowed Evans et al. (2005) to propose a growth series, starting with juveniles that matched the size, proportions and general features of the original holotype (e.g. paired frontals, interdigitated frontoparietal suture, short robust limbs, slender body profile), and progressing through to larger subadult, and finally adult specimens that showed Yabeinosaurus to be a large, well ossified lizard and not a small gecko-like one. Despite the inadequacies of the type description, we considered that the new specimens provided enough evidence a) to establish a link with the original holotype through an understanding of changes through growth, and thus permit retention of the historic name, Yabeinosaurus tenuis, and b) to develop a more detailed and realistic diagnosis based on adult 
specimens (Evans et al., 2005, Evans and Wang, 2012). The revised diagnosis (Evans and Wang, 2012) combined cranial characters (including the short maxilla, single premaxilla with nine teeth, expanded postfrontal, reduced postorbital, reduced upper temporal fenestra, dentate pterygoid and palatine, and large hook-like angular process on the mandible) with those of the postcranium (seven cervical and 19 dorsal vertebrae, perforated clavicle, small scattered osteoderms, short robust limbs). Recent specimens have also demonstrated that this lizard was predatory (based on gut contents, including fish, Evans and Wang, 2012) and viviparous (Wang and Evans, 2011).

\subsection{The problem}

The attribution of new adult and subadult material to $Y$. tenuis and the confirmation of at least specific distinction for Y. youngi led to the recognition of two Yabeinosaurus morphotypes in the Jehol Biota (Evans and Wang, 2012): one with relatively long, gracile limbs (Y. youngi), and the other with relatively shorter, more robust limbs. The latter was attributed to $Y$. tenuis on the basis of proportional resemblances between published figures of CNMM 3735 (Endo and Shikama, 1942, plates IV-VI) and the new juvenile specimens forming part of the growth series. However, the bicuspid Jingangshan lizard complicates this apparently clear dichotomy because, based on the length and morphology of the associated humerus, it also had short robust limbs. The characters that distinguish it from adults currently referred to $Y$. tenuis are in the jaw and dentition, and this creates a problem with respect to both the holotype and the neotype.

Endo and Shikama (1942) described and figured the teeth of CNMM 3735 as acutely pointed and recurved throughout the tooth row, like the teeth of adults currently referred to $Y$. tenuis rather than the new bicuspid form. However, they counted only ten maxillary teeth, and tooth number and morphology can change through ontogeny. For example, as noted above, adults of the related Japanese Sakurasaurus have blunt crushing teeth at the rear of the dentary (Evans and Manabe, 1999) but the teeth are more homodont in immature specimens (Evans and Manabe, 2009). Therefore it is not possible to determine whether the original holotype individual, a juvenile, would have developed bicuspid or unicuspid posterior teeth as an adult. Moreover, an angular process is neither figured nor mentioned in the description, and it may not have been developed at this early ontogenetic stage. Thus although it is likely, on the basis of limb proportions, that CNMM 3735 would eventually have matured into a large robust-limbed adult, rather than a gracile limbed lizard like Y. youngi, it is currently impossible to determine which of the two robust morphotypes this 
would have been (monocuspid+hooked angular process vs bicuspid+straight angular process). YPM R002 provides no resolution, because it is also too young. Given that it comes from the same locality as the bicuspid form, it may well be a juvenile of that taxon. As CNMM 3735 and YPM R002 are designated as the name bearing specimens for $Y$. tenuis, this is problematic.

\subsection{Resolution of the problem}

The group of new adult and subadult specimens previously referred to 'Yabeinosaurus tenuis' (notably IVPP V 13272, V 13284, and V 13285, from the Yixian Formation; and IVPP V 16361, V 16362, and V 18005 from the Jiufotang Formation) does form a diagnosable phylogenetic unit based on a combination of paired frontals; interdigitated frontoparietal suture; distinctive parietal with broad based postparietal processes; short, deep maxilla with sharp, inflected teeth; course linear cranial sculpture; long slender anteriorly tapering squamosal; enlarged postfrontal and reduced postorbital. Other features like the angular process, palatal dentition, and postcranial morphology are not known in all specimens but there is no inconsistency. This phylogenetic unit can be differentiated from other Jehol Biota lizard taxa, but it does appear to be closely related to the Japanese Sakurasaurus (Evans and Manabe, 1999, 2009). The adult of Dalinghosaurus (Evans and Wang, 2005; Evans et al., 2007) has fused frontals, pustulate rather than linear cranial sculpture, and exceptionally long hind limbs and feet. Liushusaurus (Evans and Wang, 2010) lacks cranial sculpture, has a smaller postfrontal, a shorter, broader parietal with no parietal foramen, a shorter broader body profile, and reaches skeletal maturity at a smaller size. With respect to other lizards from the Lower Cretaceous of China, Mimobecklesisaurus from Gansu Province has rectangular osteoderms like paramacellodids (Li, 1985); Pachygenys (Gao and Cheng 1999) from Shandong Province has a uniquely shaped jaw with shortened tooth row; and Xianglong from Liaoning Province (Li et al., 2007) is a specialised long-ribbed glider.

In order to resolve the taxonomic problem with respect to Yabeinosaurus tenuis, and in consultation with the ICZN, we considered two options. One was to make an application to the International Commission on Zoological Nomenclature (ICZN) to replace YPM R002 (as an unidentifiable neotype) with a more diagnostic adult specimen, under Article 75.5 of the code. The alternative is to leave Yabeinosaurus tenuis as a historical entity, accepting that it is a nomen dubium because of the inadequacy of both the original holotype and the designated neotype. Under this option, Y. tenuis remains the type species of the genus 
Yabeinosaurus, despite being designated a nomen dubium (Article 81.2.1 of the ICZN code), and the widely recognised genus name can be retained. A new species name, Yabeinosaurus robustus, can therefore be erected for the diagnosable unit based on adult and subadult specimens referred to $Y$. tenuis since 2005, with Y. bicuspidens sp. nov. erected for the bicuspid taxon represented by IVPP $\vee 15840$. We opted for this second solution.

\section{Conclusions.}

The genus Yabeinosaurus was the first reptile to be described from the Jehol Biota and therefore has historic significance. Unfortunately, the immaturity of the original specimen (and its subsequent loss) resulted in decades of misinterpretation and has led to problems of association. These have been highlighted by the recovery of an additional Yabeinosaurus-like morphotype with bicuspid teeth. We therefore conclude that $Y$. tenuis, the type species, should be considered as a nomen dubium. Nonetheless, the lizards hitherto referred to Yabeinosaurus appear to constitute a morphologically consistent grouping. The rules of the ICZN allow the name Yabeinosaurus to be preserved for this grouping, with $Y$. tenuis as the type species, but no further material should be referred to that species. We erect two new species, $Y$. robustus sp. nov. and Y. bicuspidens sp. nov., for the two dental morphotypes within the robust-limbed members of the genus, and retain Y. youngi provisionally for the gracile-limbed morphotype.

\section{Acknowledgements}

This collaborative project on the Jehol lizard fauna was initiated under a joint project grant from the Royal Society of London and the National Science Foundation of China, and continued under funding from the Chinese Academy of Sciences (XDB18030503) and the Ministry of Science and Technology of China (2012CB821903) (to YW), the UK Palaeontological Association, and the Chinese Academy of Sciences President's International Fellowship Initiative (2016) (to SEE). A scholarship under the State Scholarship Fund allowed LPD to spend one year in the UK. The new lizard fossil was carefully prepared by Guo Yanfang. We express our thanks to the reviewers and editors for their comments on an earlier version of the manuscript. We are also grateful to Dr Svetlana Nikolaeva, editor of the Bulletin of Zoological Nomenclature, ICZN, for advice as to how to resolve the taxonomic problems raised by the new material and uninformative holotypes. 


\section{References}

Bolet, A., and Evans, S. E. (2010). A new lizard from the Early Cretaceous of Catalonia (Spain), and the Mesozoic lizards of the Iberian Peninsula. Cretaceous Research, 31, 447-457.

Chang, M.-m., Chen, P-j., Wang, Y.-q., and Wang, Y. (2008). The Jehol Fossils: The Emergence of Feathered Dinosaurs, Beaked Birds and Flowering Plants. Academic Press, Elsevier Ltd. 1-208.

Chang, S.-c., Zhang, H.-c., Renne, P. R., and Fang, Y. (2009). High-precision 40Ar/39Ar age for the Jehol Biota. Palaeogeography, Palaeoclimatology, Palaeoecology, 280, 94-104.

Chang, S.-c, Zhang, H., Hemming, S. R., Mesko, G. T., and Fang Y. (2014). 40Ar/39Ar age constraints on the Haifanggou and Lanqi formations: when did the first flowers bloom? In: Jourdan, F., Mark, D. F., and Verati, C., (Eds.), Advances in 40Ar/39Ar dating: from archaeology to planetary sciences. Geological Society Special Publications, 378. 277-284.

Chen, J.-y., Li, W., Kiu, M., Xing, D., and Yang, J. (2015). U-Pb isotopic age of the volcanic rocks of the Yixian Formation in Jianping Machang of Western Liaoning and its geological significance. Journal of the Jilin University (Earth Science Edition), 15, 471-482. (In Chinese with English Abstract)

Eberth, D. A., Russell D. A., Braman D. R., and Deino A. L. (1993). The age of the dinosaur-bearing sedimentts at Tebch, Inner Mongolia, People's Republic of China. Canadian Journal of Earth Science, 30, 2101-2106.

Endo, R., and Shikama, T. (1942). Mesozoic reptilian fauna in the Jehol mountainland, Manchoukuo. Bulletin of the Central National Museum of Manchoukuo, 3, 1-19.

Estes R. (1983). Sauria Terrestria, Amphisbaenia. Encyclopedia of Paleoherpetology, Part 10A Gustav Fischer Verlag, Stuttgart, New York. 1-249.

Evans, S. E., and Barbadillo, L. J. (1997). Early Cretaceous lizards from Las Hoyas, Spain. Zoological Journal of the Linnean Society, 119, 23-49.

Evans, S. E., and Manabe, M. (1999). Early Cretaceous lizards from the Okurodani Formation of Japan. Geobios, 32, 889-899.

Evans, S. E., and Manabe, M. (2009). The Early Cretaceous lizards of Eastern Asia: new material of Sakurasaurus from Japan. Special Papers in Palaeontology, 81, 43-59. 
Evans, S. E., and Matsumoto, R. (2015). An assemblage of lizards from the Early Cretaceous of Japan. Palaeontologica Electronica, 18, 1-36.

Evans S. E., and Wang, Y. (2005). Dalinghosaurus, a lizard from the Early Cretaceous Jehol Biota of northeast China. Acta Palaeontologica Polonica, 50, 725-742.

Evans, S. E., and Wang, Y. (2007). A juvenile lizard specimen with well-preserved skin impressions from the Upper Jurassic/Lower Cretaceous of Daohugou, Inner Mongolia, China. Naturwissenschaften, 94, 431439.

Evans, S. E., and Wang, Y. (2010). A new lizard (Reptilia: Squamata) with exquisite preservation of soft tissue from the Lower Cretaceous of Inner Mongolia, China. Journal of Systematic Palaeontology, 8, 8195.

Evans, S. E., and Wang, Y. (2012). New material of the Early Cretaceous lizard Yabeinosaurus from China. Cretaceous Research, 34, 48-60.

Evans, S. E., Wang, Y., and Li, C. (2005). The Early Cretaceous lizard Yabeinosaurus from China: resolving an enigma. Journal of Systematic Palaeontology, 3, 319-335.

Evans, S. E., Wang, Y., and Jones, M. E. H. (2007). An aggregation of lizard skeletons from the Lower Cretaceous of China. Senckenbergiana Lethaea, 87, 109-118.

Field, A. (2005). Discovering statistics using SPSS. Second Edition. SAGE Publications, London.

Gao, K.-q., and Cheng, Z.-w. (1999). A new lizard from the Lower Cretaceous of Shandong, China. Journal of Vertebrate Paleontology, 19, 456-465.

He, H.-y., Wang, X.-I., Zhou, Z.-h., Wang, F., Boven, A., Shi, G.-h., and Zhu, R.-x., (2004). Timing of the Jiufotang Formation (Jehol Group) in Liaoning, northeastern China and its implications. Geophysical Research Letters, 31, 261-268.

He, H.-y., Wang, X.-y., Zhou, Z.-h., Jin, F., Wang, F., Yang, L.-k., Ding, X., Boven, A., and Zhu, R.-x. (2006). ${ }^{40} \mathrm{Ar} /{ }^{39} \mathrm{Ar}$ dating of Lujiatun Bed (Jehol Group) in Liaoning, northeastern China. Geophysical Research Letters, 33, 347-360.

Hoffstetter, R. (1964). Les Sauria du Jurassique supérieur et specialement les Gekkota de Baviére et de Mandchourie. Senckenbergiana Biologie, 45, 281-324.

Hoffstetter, R. (1967). Coup d'oeil sur les Sauriens (= lacertiliens) des couches de Purbeck (Jurassique 
supérieur d'Angleterre). Résumé d'un mémoire. Colloques International C.N.R.S., 163, 349-371.

Ji, S.-a. (1995). Reptiles. In: D. Ren, L.-w. Lu, Z.-g. Guo, and S.-a. Ji (Eds.), Faunae and Stratigraphy of Jurassic-Cretaceous in Beijing and the Adjacent Areas. Beijing: Seismic Publishing House. 47-176.

Ji, S.-a. (2005). A new Early Cretaceous lizard with well-preserved scale impressions from western Liaoning, China. Progress in Natural Science, 15, 162-168.

Ji S.-a., and Ren, D. (1999). First record of lizard skin fossil from China with description of a new genus (Lacertilia: Scincomorpha). Acta Zootaxonomica Sinica, 24, 118-124.

Ji, S.-a., Lu, L.-w., and Bo, H.-c. (2001). New material of Yabeinosaurus tenuis (Lacertilia). [Land and Resources] 2001(4), 41-43. [In Chinese]

Li, J.-I. (1985). A new lizard from the Late Jurassic of Subei, Gansu. Vertebrata PalAsiatica, 23, 13-18. [In Chinese with English summary].

Li, P.-p., Gao, K.-q., Hou, L.-h., and Xu, X. (2007). A gliding lizard from the Early Cretaceous of China. Proceedings of the National Academy of Sciences, USA, 104, 5507-5509.

Liang, J.-h., Gong, E.-p., and Li, Y.-j. (2012). The sedimentary facies and palaeoenvironment of Jingangshan Layer of Early Cretaceous Yixian Formation in Zaocishan Area, Yixian Basin. Acta Sedimentologica Sinica, 30, 689-695. [In Chinese with English summary]

Lü, J.-c., Ji, Q., Wei, X.-f., and Liu, Y.-q. (2012). A new ctenochasmatoid pterosaur from the Early Cretaceous Yixian Formation of western Liaoning, China. Cretaceous Research, 34, 26-30.

Pan, Y.-h., Sha, J.-g., Zhou, Z.-h., and Fürsich, F. T. (2013). The Jehol Biota: definition and distribution of exceptionally preserved relicts of a continental Early Cretaceous ecosystem. Cretaceous Research, 44, $30-38$.

Richter, A. (1994). Lacertilier aus der Unteren Kreide von Uña und Galve (Spanien) und Anoual (Marokko). Berliner geowissenschaftliche Abhandlungen, 14, 1-147.

Sweetman, S. C. (2009). A new species of the plagiaulacoid multituberculate mammal Eobaatar from the Early Cretaceous of southern Britain. Acta Palaeontologica Polonica, 54, 373-384.

Sweetman, S. C. (2016). A comparison of Barremian-early Aptian vertebrate assemblages from the Jehol Group, north-east China and the Wealden Group, southern Britain: the value of microvertebrate studies in adverse preservational settings. Palaeobiodiversity and Palaeoenvironment, 96, 149-167. 
Sweetman, S. C., and Evans, S. E. (2011). Lepidosaurs (lizards). In: D.J. Batte, (Ed.), Palaeontological Association Field Guide to Fossils, 14. English Wealden fossils. London: The Palaeontological Association. 264-284.

Swisher, C. C., Wang, X.-I., Zhou, Z.-h., Wang, Y.-q., Jin, F., Zhang, J.-y., Xu, X., Zhang, F.-c., and Wang, Y. (2002). Further support for a Cretaceous age for the feathered-dinosaur beds of Liaoning, China: New 40Ar/39Ar dating of the Yixian and Tuchengzi formations. Chinese Science Bulletin, 47, 136-139.

Wang, C., Shih, C. K., and Ren, D. (2014). A new fossil hangingfly (Mecoptera: Cimbrophlebiidae) from the Early Cretaceous of China. Acta Geologica Sinica (English Edition), 88, 29-34.

Wang, X.-l., and Zhou, Z.-h. (2003). Mesozoic Pompeii. In Chang, M.-m., Chen, P.-j., Wang Y.-q., and Wang, Y. (Eds.) The Jehol Biota. Shanghai Scientific and Technical Publishers: China. 19-35.

Wang, X.-I., and Zhou, Z.-h. (2004). Pterosaur embryo from the Early Cretaceous. Nature, 429, 621.

Wang, X.-I., Miao, D.-s., and Zhang, Y.-g. (2005). Cannibalism in a semi-aquatic reptile from the Early Cretaceous of China. Chinese Science Bulletin, 50, 282-284.

Wang, Y., and Evans, S. E. (2011). A gravid lizard from the Early Cretaceous of China: insights into the history of squamate viviparity. Naturwissenschaften, $98,739-743$.

Wang, Y.-q., Sha, J.-g., Pan, Y.-h., and Zuo, Q.-m. (2015). The Early Cretaceous non-Cypridea Ostracoda from Yixian and Jiufotang formations of western Liaoning (China). Palaeoworld, 25, 406-424.

Young, C. C. (1958). On a new locality of Yabeinosaurus tenuis Endo and Shikama. Vertebrata PalAsiatica, 2, 151-156.

Zhang, F.-c., and Zhou, Z.-h. (2004). Leg feathers in an Early Cretaceous bird. Nature, 431, 925.

Zhou, Z.-h. (2014). The Jehol Biota, an Early Cretaceous terrestrial Lagerstatte: new discoveries and implications. National Science Review, 1, 543-559.

Zhou, Z.-h., Barrett, P. M., and Hilton, J. (2003). An exceptionally preserved Lower Cretaceous ecosystem, Nature, 421, 807-814.

Zhu, R.-x., Pan, Y.-x., Shi, R.-p., Liu, Q.-s., and Li, D.-m. (2007). Palaeomagnetic and 40Ar/ 39Ar dating constraints on the age of the Jehol Biota and the duration of deposition of the Sihetun fossil-bearing lake sediments, northeast China. Cretaceous Research, 28, 171-176. 


\section{Figure captions}

Figure 1. Map of China showing all currently recorded Yabeinosaurus localities. Shaded area is enlarged and shown in detail (triangles are fossil localities). 1, Zaocishan (Tsaotzushan) Loc. (E121.17, N41.46), Yixian County, Liaoning Province; Yixian Fm., Lower Cretaceous; Holotype of Y. tenuis, CNMM3735; 2, Jingangshan Loc. (E121.14, N41.45), Yixian County, Liaoning Province; Yixian Fm., Lower Cretaceous; "neotype" of Y. tenuis, YFM-R002; holotype of Y. bicuspidens sp. nov., IVPP V 15840; juvenile specimen referred to Y. tenuis (Evans et al., 2005), IVPP V 12641, now Yabeinosaurus sp.; 3, Jianshangou Loc. (E120.88, N41.53), Shanyuan Town, Beipiao City, Liaoning Province; Yixian Fm., Lower Cretaceous; juvenile specimen referred to Y. tenuis (Ji, 1995), LBV 92009, now Yabeinosaurus sp.; 4, Sihetun Loc. (E120.80, N41.59), Beipiao City, Liaoning Province: Yixian Fm., Lower Cretaceous; holotype of Y. robustus sp. nov., IVPP V 13285; 5, Yuanjiawa Loc. (E120.11, N41.43), Dapingfang Town, Chaoyang City, Liaoning Province, Jiufotang Fm., Lower Cretaceous; referred specimen of Y. robustus sp. nov, IVPP V 13272; 6, Dawangzhangzi Loc. (E119.22, N41.19), Lingyuan City, Liaoning Province; Yixian Fm., Lower Cretaceous; referred specimen of Y. robustus sp. nov, IVPP V 13248; 7, Gezidong (Ketzutung) Loc. (E119.17, N41.14), Lingyuan City, Liaoning Province; Jiulongshan Fm., ?Middle/Upper Jurassic; holotype of Y. youngi, IVPP V 961; 8, Xiaotaizi Loc. (E119.68, N40.70), Jianchang County, Huludao City, Liaoning Province; Jiufotang Fm., Lower Cretacecous; referred specimens of Y. robustus sp. nov, IVPP V 16361, 16362, 18005.

Figure 2. Line drawing (A) and photograph (B) of the holotype (IVPP V 15840) of Yabeinosaurus bicuspidens sp. nov. The small mass of broken ribs next to the jugal is not illustrated in (A). Abbreviations: ecpt, ectopterygoid; hum, humerus; ?icl, possible interclavicle; ju, jugal; man, mandible; max, maxilla; pma, premaxilla; pt, pterygoid; scl.os, scleral ossicles; ?sq, possible squamosal (or supratemporal); ?, unknown element. Scale bars equal to $10 \mathrm{~mm}$.

Figure 3. Holotype (IVPP V 15840) of Yabeinosaurus bicuspidens sp. nov. A, premaxilla; B, pterygoid, C, squamosal or supratemporal. Abbreviations: ecpt.pr, ectopterygoid process; fs.c, fossa columellae; na.pr, nasal process of premaxilla; pal.pl, palatal plate of pterygoid; qu.pr, quadrate process of pterygoid; vo.pr, vomerine process of pterygoid. Scale bars on $A$ and $C$ equal $1 \mathrm{~mm}$, and on $B$ equals $5 \mathrm{~mm}$. 
Figure 4. Dentition of Yabeinosaurus bicuspidens sp. nov. and comparison between Y. bicuspidens sp. nov. and Y. robustus sp. nov.. A, right maxilla of Y. bicuspidens sp. nov. (holotype IVPP V 15840), the two rectangles show the position of the enlargements in (B) and (D); B, enlargement of the posterior maxillary teeth of Y. bicuspidens sp. nov. (holotype IVPP $\vee 15840$ ) (indicated by black rectangle in $[A]$ ); $C$, the 11th and 12th preserved maxillary teeth of $Y$. bicuspidens sp. nov. (holotype IVPP $\vee 15840$ ) imaged with a Keyence VHX-600EOS microscope (IVPP), red arrows show the wear facets, blue arrow indicates the incipient extra cusp; D, enlargement of the anterior maxillary teeth of Y. bicuspidens sp. nov. (holotype IVPP $\mathrm{V}$ 15840) (indicated by the white rectangle in $[\mathrm{A}]$ ); $\mathrm{E}$, posterior tooth series of the right maxilla of $Y$. robustus sp. nov. (holotype IVPP V 13285); F, anterior teeth of the left maxilla of Y. robustus sp. nov. (holotype IVPP $\mathrm{V}$ 13285); G, enlargement of the last three maxillary teeth of $Y$. robustus sp. nov. (holotype IVPP $\vee$ 13285) (indicated by white rectangle in [E]); $\mathrm{H}$, posterior part of the mandible of $Y$. robustus sp. nov. (holotype IVPP V 13285); I, posterior part of the mandible of Y. bicuspidens sp. nov. (holotype IVPP V 15840). H and I show the difference in shape of the angular process in Y. robustus sp. nov. and Y. bicuspidens sp. nov. Scale bars on $\mathrm{A}, \mathrm{E}$, and $\mathrm{F}$ equal $5 \mathrm{~mm}$, and on $\mathrm{H}$ and I equal $10 \mathrm{~mm}$.

Table 1. Measurements (in $\mathrm{mm}$ ) of the mandible and humerus length of $Y$. youngi, Y. robustus and $Y$. bicuspidens to demonstrate the difference in proportions (Humerus/Mandible as a percentage) between $Y$. youngi (long, gracile limbs) and the specimens referred to the shorter-limbed morphotypes of Yabeinosaurus, including the holotype of $Y$. bicuspidens. The value for $Y$. youngi falls well outside the 99.9\% confidence interval of $54.57 \%-30.29 \%$ for the short humerus morphotype (calculated from the formula [sample mean $\pm(3.29$ * standard deviation], Field, 2005). The sample mean is 42.429 and standard deviation of the sample is 3.69 . 


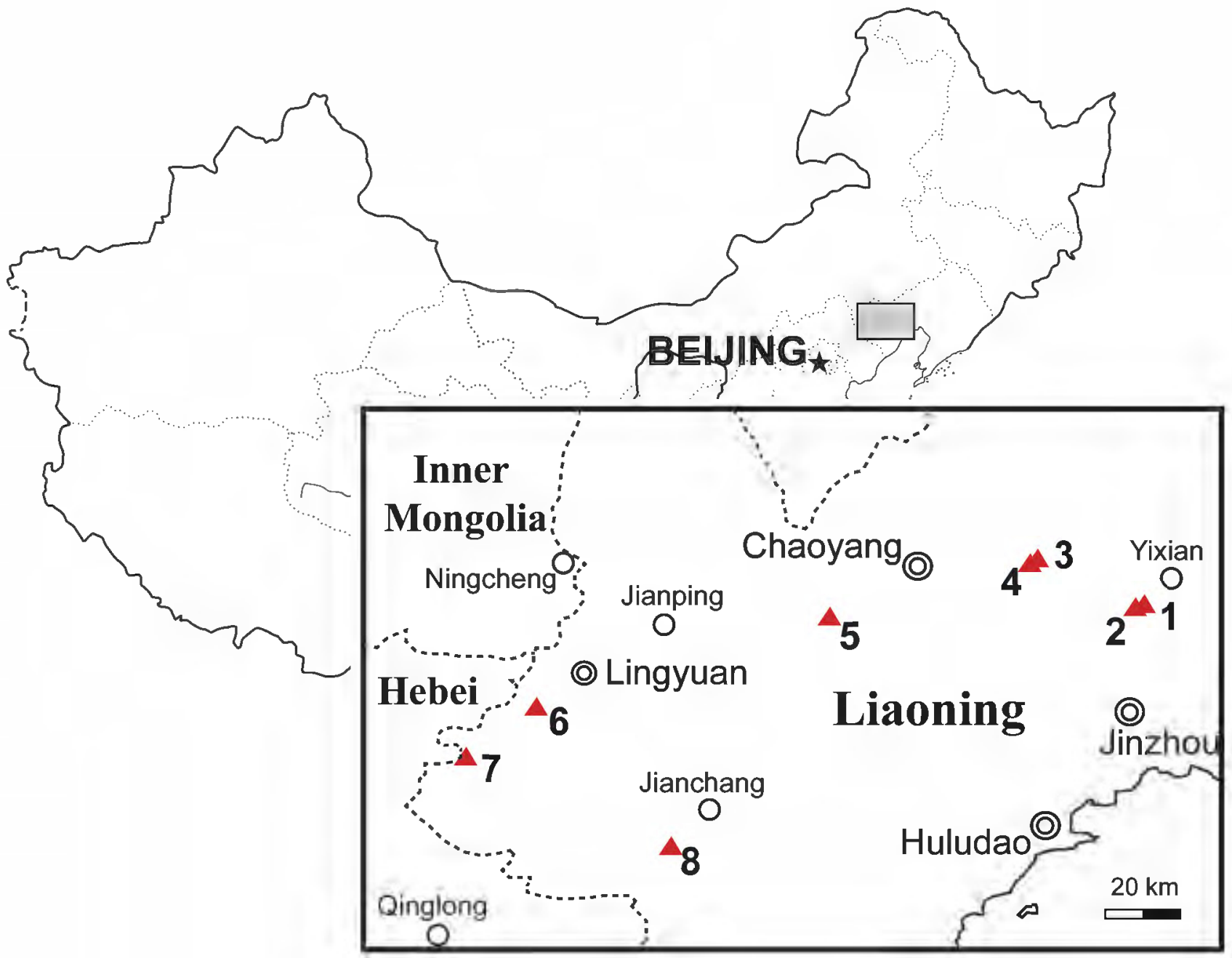



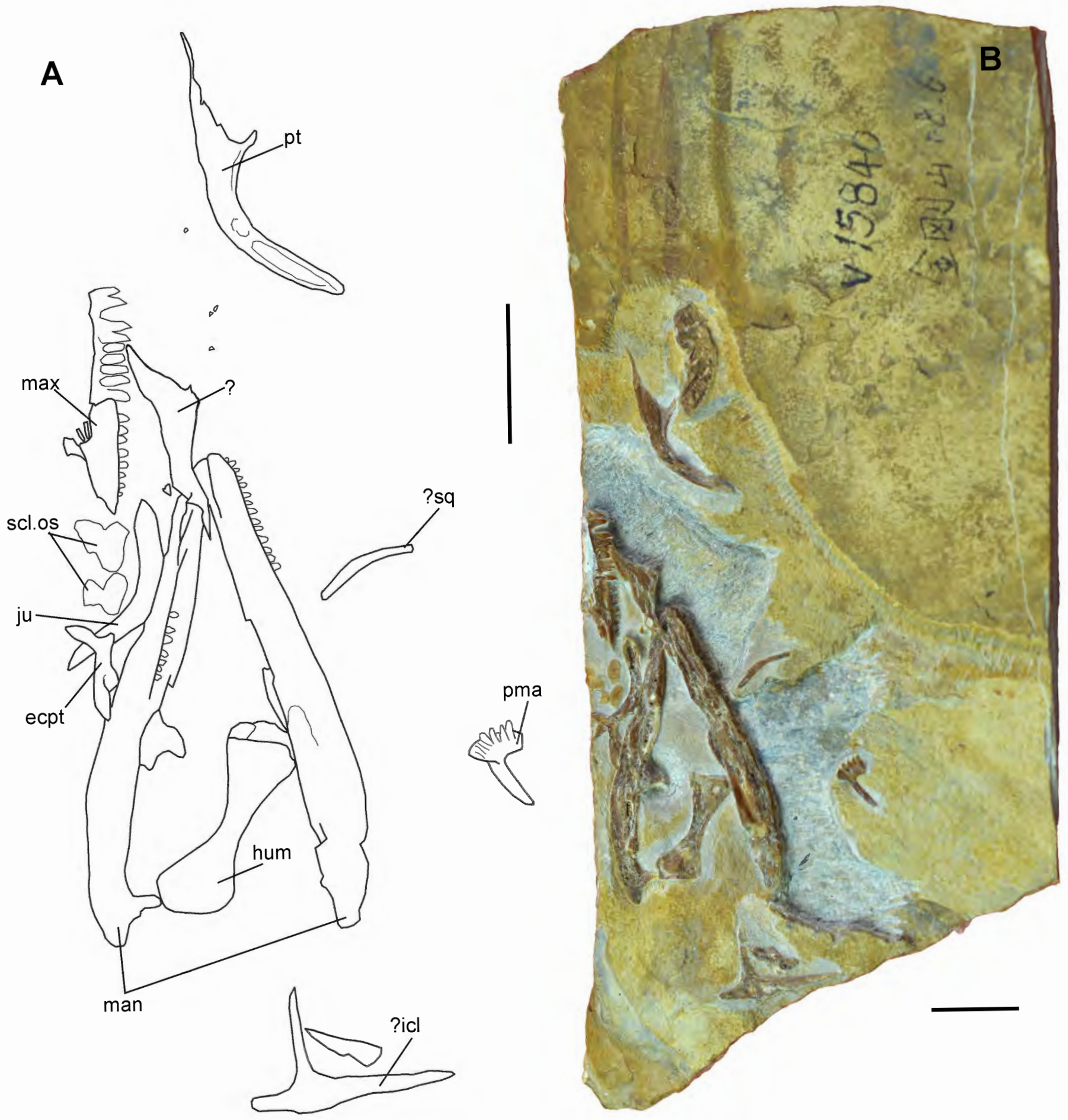
A

B qu.pr fs.c

na.pr

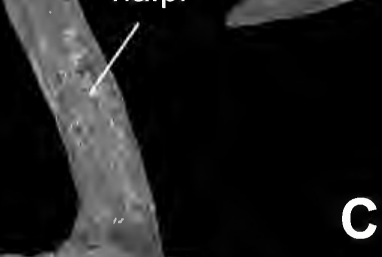

C

pal.pl
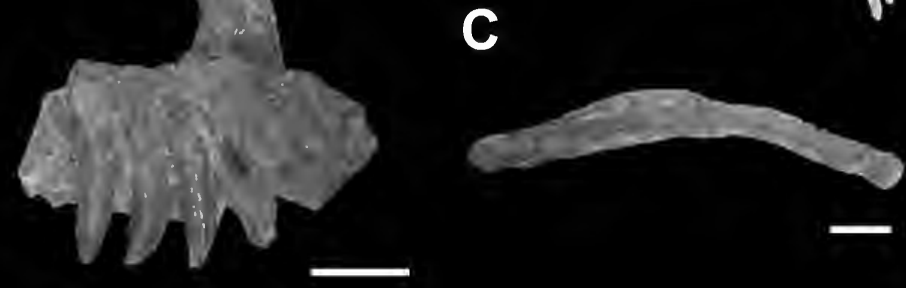


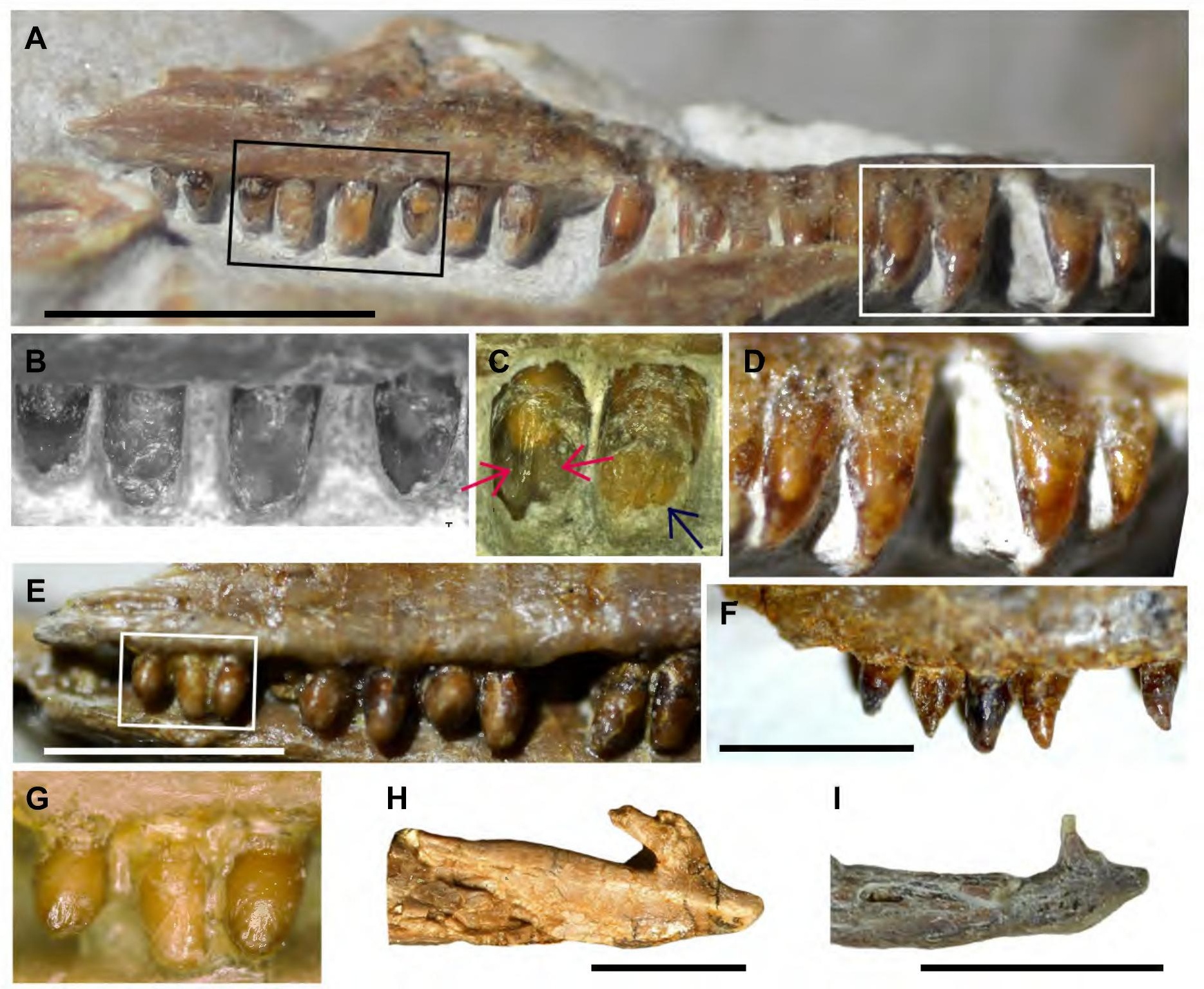




\begin{tabular}{lllll}
\hline Specimen & Mandible & Humerus & H/M\% & Comments \\
\hline IVPP V961 & 21.1 & 14.5 & $69 \%$ & Holotype of Y. youngi \\
CNMM3735 & 16.2 & 7.4 & $46 \%$ & Original holotype of 'Y. tenuis' . \\
YFM-R002 & 17.7 & 7.44 & $42 \%$ & Designated neotype of 'Y. tenuis' \\
IVPP V 12641 & 18.14 & 6.65 & $37 \%$ & Yabeinosaurus sp. \\
IVPP V 13272 & 21.6 & 10 & $46 \%$ & Referred to Y. robustus \\
IVPP V 16362 & 29.5 & 12.1 & $41 \%$ & Referred to Y. robustus \\
IVPP V 13284 & 31.7 & 14.6 & $46 \%$ & Referred to Y. robustus \\
IVPP V 15840 & 33.9 & 13.3 & $39 \%$ & Holotype of Y. bicuspidens \\
\hline
\end{tabular}

